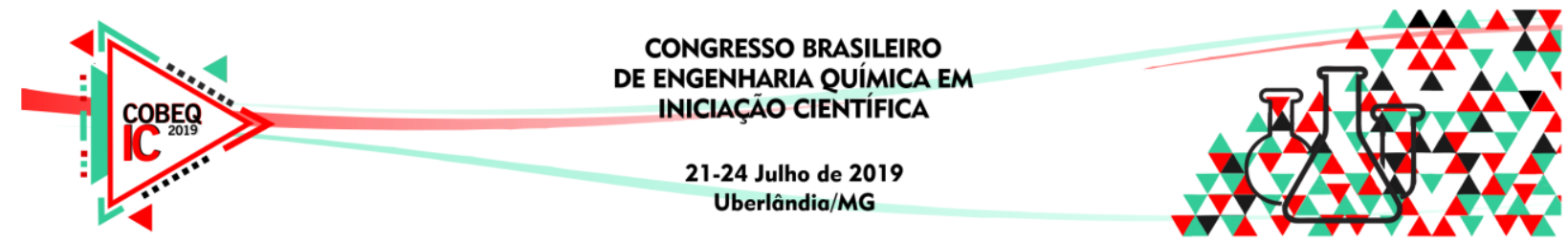

\title{
APLICAÇÃO DO PROCESSO DE COAGULAÇÃO- FLOCULAÇÃO-FILTRAÇÃO PARA REMOÇÃO DE TURBIDEZ DE EFLUENTE DE COLORAÇÃO CAPILAR
}

\author{
R. S. SYLLOS ${ }^{1}$, D. C. C. MARTINS ${ }^{1}$, T. K. F. S. FREITAS ${ }^{1}$, A. P. J. SCANDELAI ${ }^{1}$ e C. R. \\ G. TAVARES ${ }^{1}$ \\ ${ }^{1}$ Universidade Estadual de Maringá, Departamento de Engenharia Química \\ E-mail para contato: renansyllos@outlook.com
}

\begin{abstract}
RESUMO - Os efluentes gerados nos salões de beleza nos processos de coloração capilar são poluidores e necessitam de tratamento anteriormente a seu descarte. Devido às suas características o processo de coagulação-floculação-filtração (CFF) é indicado como um pré-tratamento ao seu descarte ou envio à rede coletora de esgoto. Diante disso, este estudo teve como objetivo caracterizar e tratar três efluentes distintos de tintura capilar pelo processo de CFF, utilizando coagulante natural (Tanfloc) e polimérico (PAC), visando a remoção da turbidez. Para o estudo foram coletados três efluentes de processos distintos de coloração capilar (pigmentação loira, marrom e castanha). As respostas do processo de CFF diferiram para os três efluentes tratados, no entanto, para todas as condições avaliadas as remoções foram superiores a 90\%. As melhores eficiências de remoção de turbidez, para os três efluentes avaliados, foram superiores a $99 \%$ e obtidas com o uso de coagulante PAC, em pH 7,00 em 200,0 $\mathrm{mg} \mathrm{L}^{-1}$ para o efluente 1 , e pH 8,00 em $300 \mathrm{mg} \mathrm{L}^{-1}$ para os efluentes 2 e 3 .
\end{abstract}

\section{INTRODUÇÃO}

O tratamento inadequado de efluentes, assim com seu descarte in natura no solo e em corpos hídricos impactam e comprometem a saúde ambiental dos ecossistemas. Em vista desta prática, atualmente um dos maiores problemas enfrentados é a presença de poluentes recalcitrantes e emergentes nas águas subterrâneas e superficiais, como fármacos (SernaGalvis et al., 2019) e produtos cosméticos e de higiene pessoal (Biel-Maeso et al., 2019).

Paralelamente a este cenário, o setor da beleza no Brasil tem apresentado na última década um crescimento anual de 10\% (Rodrigues et al., 2016). Dentre as atividades que compõem esse setor, os salões de beleza têm ganhado espaço no mercado, de maneira que, entre o período de 2012 a 2016, o número de estabelecimentos quase quadruplicou, sendo estimado que atualmente haja mais de um milhão de estabelecimentos no país (Sebrae, 2017; Bast, 2016).

Nos salões de beleza, o principal segmento é o de estética capilar, que engloba serviços de corte, penteado, alongamento, alisamento, hidratação, descoloração e coloração. Para todos esses processos de embelezamento, a água é um dos principais insumos. A cada serviço químico prestado, estima-se que sejam utilizados de 15 a $20 \mathrm{~L}$ de água no processo de 


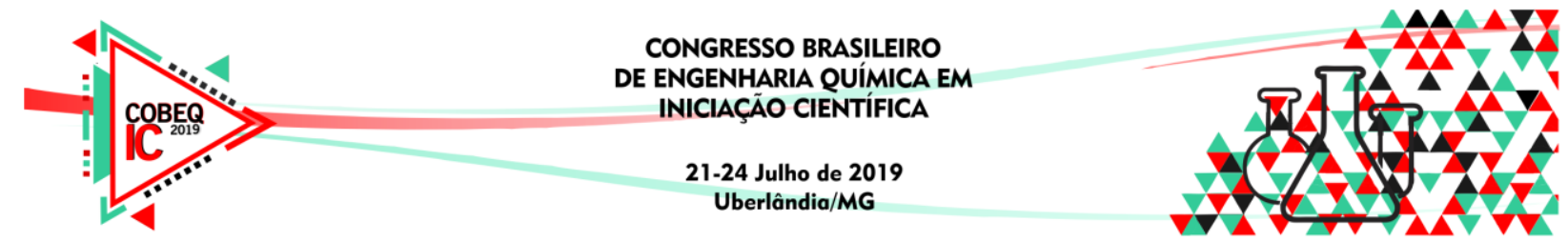

lavagem dos cabelos, os quais são convertidos em efluentes nos lavatórios de cabelo (Rodrigues et al., 2016; Sebrae, 2016). Esse efluente, embora seja complexo e variável de acordo com o processo de estética aplicado, de maneira geral, é composto por água, shampoos, condicionadores, tinturas, descolorantes e resíduos capilares. Apresentam como característica elevada cor, turbidez e matéria orgânica, predominantemente recalcitrante, sólidos suspensos e dissolvidos e toxicidade (Sebrae, 2007; Micolich, 2013).

O efluente gerado nos salões, via de regra, ou é descartado diretamente no ambiente ou é incorporado à rede coletora de esgoto. No entanto, suas características o aproximam muito mais a um efluente industrial do que ao urbano (Ajuzie e Osaghae, 2011), motivo pelo qual o sistema convencional de tratamento de esgoto nem sempre é eficiente para seu tratamento, contribuindo com a contaminação das águas superficiais com produtos cosméticos e de cuidados pessoais (Brausch e Rand, 2011).

O tratamento adequado para o efluente gerado nos lavatórios de salão de beleza é, dessa forma, uma necessidade. Nesse contexto, levando em consideração as características desse efluente, a coagulação-floculação-filtração torna-se um processo em potencial para o seu prétratamento anteriormente ao seu descarte ou envio à rede coletora de esgoto, uma vez que grande parte de seus poluentes se encontram na forma coloidal.

Assim, este estudo teve como objetivo caracterizar e tratar três efluentes distintos de tintura capilar pelo processo de coagulação-floculação-filtração, utilizando coagulante natural e polimérico, visando a remoção da turbidez.

\section{MATERIAIS E MÉTODOS}

Os efluentes foram coletados em um salão de beleza na região de Maringá-PR. Foram utilizados três efluentes de processo de coloração capilar: tintura loira (efluente 1), marrom (efluente 2) e castanha (efluente 3). Os mesmos foram caracterizados com relação aos parâmetros de $\mathrm{pH}$, turbidez, cor aparente, sólidos totais (ST), sólidos suspensos totais (SST) e sólidos dissolvidos totais (SDT), de acordo com metodologias propostas pelo Standard Methods for the Examination ofs Water and Wastewater (APHA, 1998).

A atividade coagulante tanto do coagulante natural a base de tanino (Tanfloc SG) quanto do polimérico a base de policloreto de alumínio (PAC) foi avaliada em relação ao efeito do $\mathrm{pH}(7,00$ e 8,00$)$ e concentração do coagulante $\left(100,0 ; 200,0\right.$ e $\left.300,0 \mathrm{mg} \mathrm{L}^{-1}\right)$. O ajuste de $\mathrm{pH}$ em todos os efluentes foi realizado pela adição de soluções aquosas de $\mathrm{HCl}(1,0$ mol L ${ }^{-1}$ ) ou $\mathrm{NaOH}\left(1,0 \mathrm{~mol} \mathrm{~L}^{-1}\right)$ e medido em pHmetro digital (marca Digimed, modelo DM22 , precisão de $0,05 \%$ ) utilizando um eletrodo combinado de $\mathrm{pH}$ de vidro- $\mathrm{Ag} / \mathrm{AgCl}$ (marca Digimed, modelo DME-CV1, faixa de leitura de 1,0-14,0).

Todos os ensaios de coagulação-floculação (CF) foram realizados pelo teste de jarros (Jar Test, marca Milan, modelo JT 102/6) e em triplicatas de amostras. Os testes de CF foram realizados com $150 \mathrm{~mL}$ de amostra com $\mathrm{pH}$ previamente ajustado de acordo com cada ensaio. Em todos eles, as amostras foram submetidas a $1 \mathrm{~min}$ de agitação rápida (120 rpm), seguida de $15 \mathrm{~min}$ de agitação lenta $(20 \mathrm{rpm})$. Sequencialmente, o efluente foi filtrado em papel filtro quantitativo faixa branca (marca Unifil), uma vez que, de acordo com Richter (2009), o mesmo simula a ação de um filtro real, este processo foi denominado coagulação-floculação- 


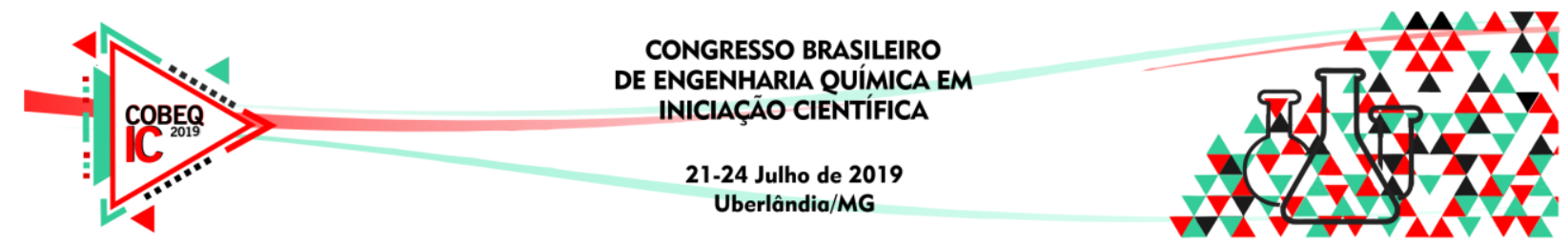

filtração (CFF). A eficiência do processo foi avaliada pela remoção da turbidez de acordo com a Equação 1.

$$
\% \text { Remoção }=\frac{T_{\text {inicial }}-T_{\text {final }}}{T_{\text {inicial }}} \times 100
$$

Em que: $\mathrm{T}_{\text {inicial }}$ e $\mathrm{T}_{\text {final }}$ são a turbidez do efluente, dada em NTU, antes e após o tratamento, respectivamente.

\section{RESULTADOS E DISCUSSÃO}

\subsection{Características do Efluente}

As características físico-químicas dos efluentes coletados estão apresentadas na Tabela 1. É possível observar que, embora os três efluentes sejam de processos distintos de coloração capilar, todos apresentaram pH básico, próximo a 8,00. Pinheiro (2016) aborda que a abertura da cutícula do fio do cabelo, necessária para o processo de despigmentação da cor natural do fio e pigmentação com os corantes da tinta, ocorre em $\mathrm{pH}$ entre 8,00 e 10,0 justificando os valores encontrados.

Tabela 1 - Características físico-químicas dos efluentes a serem tratados

\begin{tabular}{|c|c|c|c|c|}
\hline Parâmetro & Efluente $1^{a}$ & Efluente $2^{b}$ & Efluente $3^{c}$ & $\begin{array}{c}\text { Média } \pm \text { desvio } \\
\text { padrão }\end{array}$ \\
\hline $\mathrm{pH}$ & 8,10 & 7,60 & 8,00 & $7,9 \pm 0,3$ \\
\hline Cor aparente $\left(\mathrm{mg} \mathrm{PtCo} \mathrm{L}^{-1}\right)$ & 3700 & 5500 & 6200 & $5133 \pm 1290$ \\
\hline Turbidez (NTU) & 975 & 928 & 803 & $902 \pm 89$ \\
\hline $\mathrm{ST}\left(\mathrm{mg} \mathrm{L}^{-1}\right)$ & 1253 & 690 & 1310 & $1084 \pm 343$ \\
\hline $\operatorname{SST}\left(\mathrm{mg} \mathrm{L}^{-1}\right)$ & 980 & 385 & 305 & $557 \pm 369$ \\
\hline $\operatorname{SDT}\left(\mathrm{mg} \mathrm{L}^{-1}\right)$ & 273 & 305 & 1005 & $528 \pm 414$ \\
\hline
\end{tabular}

Efluentes referentes às colorações: (a) loira, (b) marrom e (c) castanha.

Fonte: autores.

Os valores de cor aparente e turbidez foram elevados nos três efluentes analisados e podem ser explicados devido à grande presença de SDT e SST no meio aquoso, respectivamente. Foi observado que, quanto maior a concentração de SDT, maior contribuição para o aumento na cor aparente do efluente, podendo ser verificado, ainda, um aumento na cor aparente com o aumento da pigmentação da tinta. Também se verificou que um aumento na quantidade SST ocasionou um aumento na turbidez. Porém, foi observado um efeito contrário à cor aparente, em que um aumento da pigmentação de tinta diminui a turbidez. A turbidez do efluente ocorre principalmente pela presença de cremes e condicionadores provenientes tanto da pasta de tintura, quanto do enxague e hidratação realizados posteriormente ao tingimento do cabelo, enquanto que a cor aparente é decorrente da presença de pigmentos.

\subsection{Tratamento por Coagulação-floculação-filtração (CFF)}




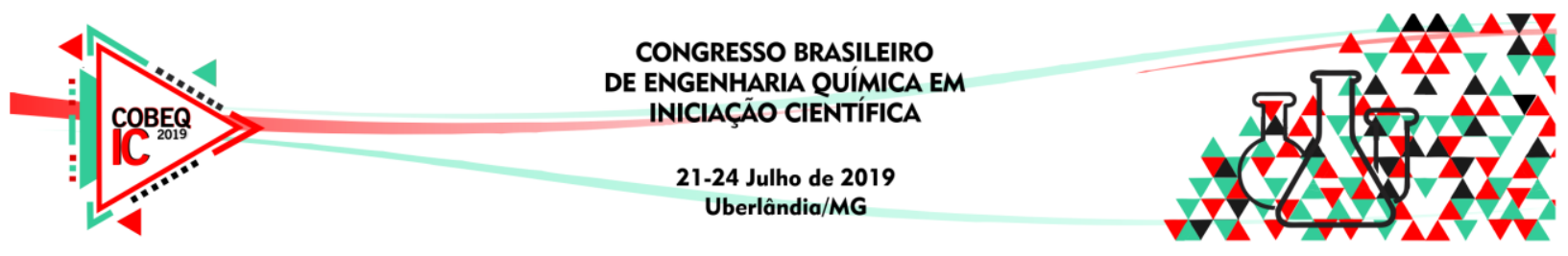

A eficiência do tratamento por CFF dos três efluentes nas condições operacionais estudadas estão apresentados na Tabela 2.

Tabela 2 - Eficiência das remoções de turbidez obtida pelo tratamento por coagulaçãofloculação-filtração

\begin{tabular}{|c|c|c|c|c|c|}
\hline \multicolumn{3}{|c|}{ Condições experimentais } & \multicolumn{3}{|c|}{ Remoções (\%) \pm Desvio padrão } \\
\hline $\mathbf{p H}$ & Coagulante & $\begin{array}{c}\text { Concentração } \\
\text { coagulante }\left(\mathrm{mg} \mathrm{L}^{-1}\right)\end{array}$ & Efluente $1^{\mathrm{a}}$ & Efluente $2^{b}$ & Efluente $3^{c}$ \\
\hline 7,00 & PAC & 100,0 & $99,63 \pm 0,36^{a}$ & $98,76 \pm 0,30^{\mathrm{a}}$ & $97,39 \pm 0,76^{\mathrm{a}}$ \\
\hline 7,00 & PAC & 200,0 & $99,90 \pm 0,03^{b}$ & $99,77 \pm 0,09^{b}$ & $98,80 \pm 0,46^{\mathrm{b}}$ \\
\hline 7,00 & PAC & 300,0 & $99,80 \pm 0,03^{\mathrm{c}}$ & $99,86 \pm 0,01^{\mathrm{c}}$ & $99,24 \pm 0,22^{c}$ \\
\hline 7,00 & Tanfloc & 100,0 & $99,27 \pm 0,26^{\mathrm{a}}$ & $94,14 \pm 3,16^{\mathrm{d}}$ & $89,78 \pm 0,34^{\mathrm{d}}$ \\
\hline 7,00 & Tanfloc & 200,0 & $99,12 \pm 0,75^{\mathrm{a}}$ & $95,16 \pm 2,84^{\mathrm{a}}$ & $90,78 \pm 0,57^{\mathrm{e}}$ \\
\hline 7,00 & Tanfloc & 300,0 & $99,41 \pm 0,36^{\mathrm{a}}$ & $96,56 \pm 2,15^{\mathrm{a}}$ & $94,52 \pm 1,87^{\mathrm{f}}$ \\
\hline 8,00 & PAC & 100,0 & $99,69 \pm 0,13^{\mathrm{a}}$ & $96,39 \pm 1,33^{\mathrm{a}}$ & $94,77 \pm 0,39^{g}$ \\
\hline 8,00 & PAC & 200,0 & $99,72 \pm 0,09^{\mathrm{d}}$ & $99,35 \pm 0,39^{\mathrm{e}}$ & $97,70 \pm 0,62^{h}$ \\
\hline 8,00 & PAC & 300,0 & $99,83 \pm 0,03^{\mathrm{e}}$ & $99,87 \pm 0,03^{f}$ & $99,33 \pm 0,05^{i}$ \\
\hline 8,00 & Tanfloc & 100,0 & $98,64 \pm 0,22^{f}$ & $94,40 \pm 1,72^{\mathrm{g}}$ & $91,48 \pm 0,37^{\mathrm{j}}$ \\
\hline 8,00 & Tanfloc & 200,0 & $99,24 \pm 0,29^{a}$ & $95,47 \pm 1,01^{\mathrm{a}}$ & $92,74 \pm 1,02^{\mathrm{k}}$ \\
\hline 8,00 & Tanfloc & 300,0 & $99,65 \pm 0,18^{\mathrm{a}}$ & $95,22 \pm 1,77^{\mathrm{a}}$ & $94,53 \pm 0,87^{1}$ \\
\hline
\end{tabular}

Efluentes referentes às colorações: (a) loira, (b) marrom e (c) castanha.

Em negrito constam as melhores remoções de turbidez obtidas para a CFF de cada efluente.

Letras iguais na mesma coluna indicam que não há diferença significativa pelo Teste de Tukey $(p>0,05)$.

Fonte: autores.

Todas as condições de tratamento apresentaram excelente desempenho com remoções de turbidez superiores a $90 \%$ (Tabela 2). No entanto, os três efluentes processados apresentaram diferentes respostas de remoção de turbidez para as condições experimentais avaliadas, sendo coerente com a distinção de suas características físico-químicas iniciais (Tabela 1). Os Testes de Tukey realizados mostraram que, para os três efluentes, os melhores e piores valores de remoção de turbidez obtidos foram significativamente diferentes entre si.

Para o efluente 1, a melhor eficiência de remoção $(99,90 \%)$ ocorreu com o uso do coagulante PAC, em pH 7,00 em concentração de $200,0 \mathrm{mg} \mathrm{L}^{-1}$. Já a menor remoção $(98,64 \%)$ ocorreu com o uso do coagulante natural Tanfloc, em pH 8,00 em 100,0 $\mathrm{mg} \mathrm{L}^{-1}$.

Para o efluente 2, as maiores e menores remoções de turbidez $(99,87$ e 94,40\%, respectivamente), ocorreram para as condições experimentais $\mathrm{pH} 8,00, \mathrm{PAC}, 300,0 \mathrm{mg} \mathrm{L}^{-1} \mathrm{e}$ pH 8,00, Tanfloc, $100 \mathrm{mg} \mathrm{L}^{-1}$.

A melhor eficiência de tratamento do efluente 3 (99,33\% de remoção de turbidez), por

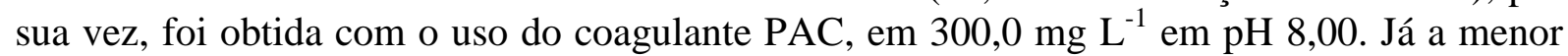
remoção de turbidez ocorreu em condição experimental de pH 7,00 utilizando Tanfoc em $100,0 \mathrm{mg} \mathrm{L}^{-1}$. 


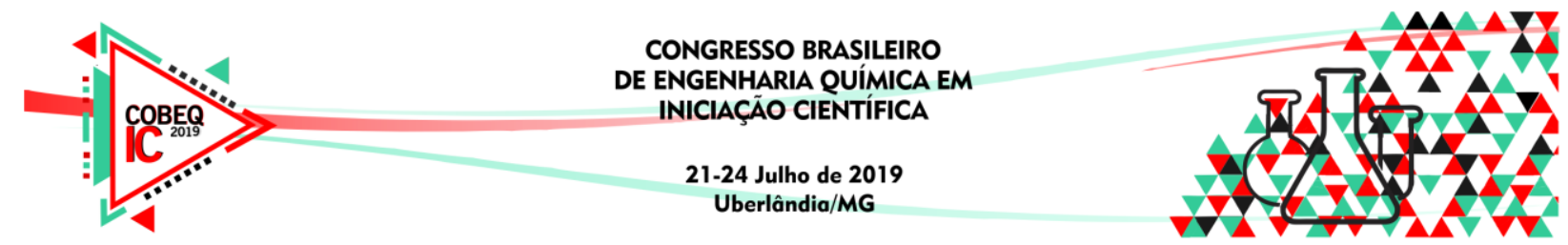

De um modo geral, o coagulante PAC, por ser um coagulante polimérico, apresentou melhor desempenho no processo de CFF dos efluentes avaliados, gerados ao final de processo de coloração capilar.

Embora para os três efluentes o coagulante Tanfloc tenha apresentado o pior desempenho, quando utilizado em sua menor concentração experimentada, para todas as condições no qual o mesmo foi avaliado, as remoções de turbidez foram superiores a $90 \%$ e, em alguns casos, se aproximou ao desempenho do coagulante PAC. Sua utilização, embora não seja tão eficiente quanto à do PAC, não deve ser descartada, uma vez que, além de também ser um coagulante comercial, possui as vantagens de ser de origem natural e gerar um lodo mais biodegradável e menos impactante ao ambiente, quando comparado ao coagulante metalizado.

\section{CONCLUSÕES}

O processo de CFF apresentou excelente desempenho diante da remoção da turbidez dos três efluentes tratados, apresentando, em todas as condições experimentais avaliadas, eficiências de remoção superiores a $90 \%$.

Para os três efluentes a melhor remoção de turbidez ocorreu com a utilização do coagulante PAC. Para o efluente 1 na condição de $\mathrm{pH} 7,00$ e concentração de $200,0 \mathrm{mg} \mathrm{L}{ }^{-1}$ (99,90\%), e para os efluentes 2 e 3 em pH 8,00 em $300 \mathrm{mg} \mathrm{L}^{-1}$ (99,87 e 99,33\%, respectivamente). No entanto, devido às vantagens em se utilizar um coagulante natural, e às elevadas eficiências alcançadas nesse estudo (acima de 90\%), o uso do Tanfloc para a remoção de turbidez de efluentes de salão de beleza pode ser considerada.

\section{REFERÊNCIAS}

AJUZIE, C. U.; OSAGHAE, B. A. The bacterial and physico-chemical properties of hairsalo wastewater and contaminated soil in Benin metropolis. Afri. J. Biotechnol., v. 11, n. 11, p. 2066-2069, 2011.

AMERICAN PUBLIC HEALTH ASSOCIATION (APHA). Standard methods for the examination of water and wastewater. 20. ed. USA: APHA, 1998.

BAST, E. Número de salões de beleza quase quadruplicou nos últimos quatro anos. Jornal Hoje, São Paulo, 8 set. 2016. Disponível em: <http://g1.globo.com/jornalhoje/noticia/2016/06/numero-de-saloes-de-beleza-quadruplicou-nos-ultimos-quatroanos.html>. Acesso em: 20 set. 2018.

BIEL-MAESO, M.; CORADA-FERNÁNDEZ, C.; LARA-MARTÍN, P. A. Removal of personal care products (PCPs) in wastewater and slugde treatment and their occurrence in receiving soils. Water Res., v. 150, p. 129-139, 2019.

BRAUSCH, J. M.; RAND, G. M. A review of personal care products in the aquatic environment: environmental concentration and toxicity. Chemosphere, v. 82, p. 15181532, 2011. 


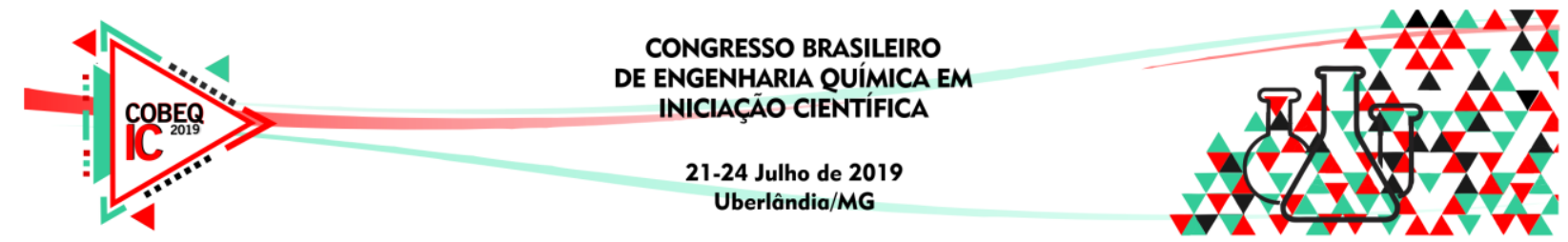

MICOLICHI, V. P. Estudo da potencialidade de degradação de efluentes de centros estéticos através de processos fenton e foto-fenton. 2013. Trabalho de Conclusão de Curso (Tecnologia em Química Ambiental), Universidade Tecnológica Federal do Paraná, Curitiba, 2013.

PINHEIRO, A. S. A arte de colorir os cabelos. Kosmoscience, ago. 2016. Disponível em:< https://www.kosmoscience.com/artigo-interno.php?id=31>. Acesso em 20 out. 2018.

RICHTER, C. Água: métodos e tecnologias de tratamento. São Paulo: Blucher, 2009.

RODRIGUES, J. C.; OLIVEIRA, J. T.; PIRES, M. J. R.; BERNARDES, A. M.; HEBERLE, A. Estudo da oxidação fotoquímica em efluentes líquidos gerados em salões de beleza. In: Simpósio Internacional de Qualidade Ambiental, 10, 2016, Porto Alegre. Anais... Porto Alegre: ABES-RS/PUCRS, 2016, p. 1-11.

SEBRAE. Minha empresa sustentável: Salão de beleza. Cuiabá: Centro Sebrae de Sustentabilidade, $2016 . \quad$ Disponível em: $<$ http://sustentabilidade.sebrae.com.br/Sustentabilidade/Para\%20sua\%20empresa/Public a\%C3\%A7\%C3\%B5es/Salao_Beleza_ONLINE.pdf>. Acesso em: 20 set. 2018.

SEBRAE. Relatório consolidado projeto salão de beleza: redução de desperdício e eficiência energética. Brasília/DF: SEBRAE, 2007. Disponível em: < http://intranet.df.sebrae.com.br/download/ambiental/Relatorios/2007/Consolida\%C3\%A 7\%C3\%A3o\%20salao\%20de\%20beleza.pdf>. Acesso em: 7 abr. 2018.

SEBRAE. Saiba como montar um salão de beleza. Minas Gerais: SEBRAE/MG, 2017. Disponível em:

https://www.sebraemg.com.br/atendimento/bibliotecadigital/documento/CartilhaManual-ou-Livro/Como-montar-um-Salao-de-Beleza >. Acesso em: 20 set. 2018.

SERNA-GALVIS, E. A.; BOTERO-COY, A. M.; MARTÍNEZ-PACHÓN, D.; MONCAYOLASSO, A.; IBÁÑEZ, M.; HERNÁNDEZ, F.; TORRES-PALMA, R. A. Degradation of seventeen contaminants of emerging concern in municipal wastewater effluents by sonochemical advanced oxidation process. Water Res., v. 154, p. 349-360, 2019. 